\title{
Monitoring service utilization of persons with mental disorders - a case for mapping pathways of care
}

\author{
H. Katschnig* \\ Medical University of Vienna and Ludwig Boltzmann Institute for Social Psychiatry, Vienna, Austria
}

Routinely collected and reported indicators for health service utilization have traditionally been event/episode related and hospital centered. This is also the case for service utilization by persons with mental disorders, for whom national and international databases usually report rates of hospital discharges, mean length of stay for hospital episode and the like. Such event/episode-related indicators are of limited use for planning and improving services for persons with mental disorders. It is argued that new reporting systems are needed that allow the monitoring of the pathways of persons with mental disorders through the service system. It is shown how - owing to recent developments in techniques of 'pseudonymization' and the ever-increasing computer power for dealing with large volumes of patient data - such a system can be established and how it can contribute to analyzing empirically such mental health-care issues as 'heavy utilizers', 'revolving door psychiatry', 'continuity of care', 'de-institutionalization' and the like. Results of a record linkage study for the total population of a federal state of Austria monitoring both psychiatric and non-psychiatric health service utilization are reported. Some unexpected findings include the high utilization of non-psychiatric services by patients discharged from a psychiatric hospital bed, results which could not have been found by psychiatric case registers which usually only monitor utilization of psychiatric services.

Key words: mental health care, service utilization, pathways of care, record linkage.

Health-care reform has become one of the top political agendas worldwide. At first sight, the ever-rising costs - mainly due to medical progress and the aging society - are the driving force of these discussions. But a closer look shows that also more fundamental issues show up behind the scene. Is the money used in the best way, i.e. are quality of care and cost efficiency an issue? Are different financing mechanisms of health care related to better or worse outcome? Whose responsibility is health care, the state's or one's own? Is there equity in access to health care? Should there be universal health-care coverage for health risks? Some of these questions can only be answered by value judgments; however, also these, in addition to most of the other questions, would need a sound empirical knowledge base on how a given health system is functioning and fulfilling its purpose.

Such knowledge exists only in rudimentary form. In particular, it is not yet possible to compare in a conclusive way different health-care systems in terms of their relative performance and efficiency, since no agreed-upon strategies exist on which categories and on which indicators to rely in such comparisons.

* Address for correspondence: Heinz Katschnig, MD, Professor of Psychiatry, Medical University of Vienna, Director, Ludwig Boltzmann Institute for Social Psychiatry, Lazarettgasse 14A-912, A-1090 Vienna, Austria.

(Email: heinz.katschnig@meduniwien.ac.at)
While attempts exist to define essential categories for such comparisons (e.g. Kutzin, 2001; Wendt et al. 2009), international comparisons are still dominated by contrasting simple 'indicators', such as mortality rates, staffing ratios or hospital episodes. While some of these 'indicators' are useful, others are obviously reported because they are available, but may not have much relevance.

Actually, indicators relating to the health-care systems are available in several international databases (OECD, 2010; EUROSTAT, 2010; WHO-HFA, 2010), but their meaning and quality are often questionable, especially as far as mental health is concerned (Katschnig et al. 2006). As a rule, service utilization is represented in these databases mainly by hospital data (e.g. rate of beds, rate of discharges from hospital beds and average length of stay of hospital episodes). This is especially problematic for mental health care, which mainly takes place outside the hospital. Practically no routinely reported information exists for use of 'extramural' mental health care, and if so, then such information stems from household surveys and not from actual service use data (EC, October 2010).

In addition, as a rule reported service utilization data refer to events (e.g. discharges from hospital) and are not related to persons, so that repeated use or utilization of several services by the same person cannot be monitored. In a recent review on performance assessment in mental health services (Jacobs \& 
McDaid, 2009), the authors bemoan the lack of the possibility to link patient records within and across services, and, in a similar stance, a recent OECD report deplores that the absence of unique patient identifiers in many countries does not allow the tracking of patients across facilities (Garcia Armesto et al. 2008).

In most countries data about service utilization stem from administrative records and provider payment documentation, and the more fragmented a healthcare system is, the more difficult it is to link such service utilization data for describing pathways of care. Obstacles to describing such pathways of care have included fragmented ownership of service use data, lack of comparability of semantics of such data in different databases, data protection concerns, lack of computer power in view of the very large quantities of service use records and others.

But why should it be desirable to link patient records on a routine basis within and across services, and why especially for persons with mental disorders? Assuming that such linkage is possible, what benefits could arise from such pathway data for planning and evaluating mental health care?

\section{Potential uses of mapping service pathways of persons with mental disorders}

Depending on which service records can in fact be linked with each other in a given country or region, the potential uses of describing pathways are manifold and can help to answer many questions that are relevant to politicians, economists, patients and family members, both for improving quality of care for persons with mental disorders and for containing costs.

It should be made clear, however, that pathways of care as such say nothing about the actual quality of care provided and about the outcome of such care. But they can capture some hitherto neglected characteristics of the service systems that may be related to quality of care and could be studied in more detail. And this is especially the case for mental health care.

In view of the internationally acknowledged policy of moving the focus of mental health care from hospital to the community in a balanced way (Thornicroft \& Tansella, 2002; WHO, 2005), such information about pathways would be especially relevant. The question of whether the aim of avoiding hospital admission, especially avoiding high readmission rates ('revolving door psychiatry'), is achieved and why and why not, can only be answered in depth by linking hospital records with those of health services outside the hospital (Durbin et al. 2007; Botha et al. 2010; Byrne et al. 2010). But there are quite a few other reasons as to why knowledge about pathways of care is useful, such as examining the reality of what is often advocated as 'continuity of care' (Burns et al. 2009) and of 'de-institutionalization' (which often seems to be 'trans-institutionalization' from hospital to nursing homes and the like residential facilities), as well as research about 'dropping out of care' (Rossi et al. 2005). Also more general concepts, such as the effect of financial incentives on service use patterns (e.g. 'cream skimming'; Lave, 2003), the phenomenon of 'heavy utilizers' (Krautgartner et al. 2002), furthermore the concepts of 'pathways to care' (Goldberg \& Huxley, 1980; Amaddeo et al. 2001), 'patient career' (Jones et al. 2009), the effects of 'discharge planning' (Weyns et al. 2006) and others could be analyzed using such pathway data.

In more general terms, routinely available information about such pathways of service utilization by persons suffering from mental disorders would allow: (1) to show effects of interventions in the health-care system (such as creating new types of services, changing payment systems, etc.) on service utilization by specific groups of patients, (2) to compare the influence of different health-care and financing systems in different regions or countries on service utilization, and (3) to calculate comprehensive and real costs of service utilization (e.g. by accounting for duplication of service use) and monitor them over time.

In the following sections, the currently available event-related indicators for service utilization by persons with mental disorders will be discussed and criticized. Thereafter, ways of how pathways of care can be mapped will be described, i.e. how records from different services can be linked on a routine basis by using pseudonymization of personal identification data. Results from a study recently conducted in Austria with routinely collected service utilization data will be used to demonstrate the feasibility of such record linkage. The relevance and power of such an approach are documented by some counterintuitive results (Katschnig et al. 2010b).

The status quo of reporting service utilization by persons with mental disorders: Focus on episodes of hospital care

Both on a country and an international level, routinely reported indicators for service use by patients with mental disorders, are usually restricted to

(1) hospital data,

(2) specialized psychiatric services and to

(3) events/episodes of care.

Each of these aspects needs closer scrutiny. 


\section{Reporting hospital episodes and the increasing complexity of the service system}

In his novel 'Riven Rock', T.C. Boyle tells the story of Stanley McCormick, the young heir of an exceptionally rich family in the USA. Stanley McCormick suffered from a psychosis, and in the 1920s (when the story based on authentic events took place) the only societal response was to send such patients to a mental hospital. McCormick's parents were in a position to create an own 'mental hospital' for their son in California, staffed by nurses and doctors and which the patient could not leave for the rest of his life.

At that time treatments were not really effective, as T.C. Boyle impressively describes. The structure of psychiatric services was simple. One large institution, an 'asylum', responsible for a catchment area admitted patients. Monitoring mental health service utilization was simplehospitals just reported the number of admissions, deaths, escapes and discharges (Healy et al. 2001).

With the advent of community psychiatry in many industrialized countries over the last 50 years, psychiatric service structures have become increasingly complex, not only in terms of many different new types of services outside the hospital but also concerning the fragmentation of payment of the different providers of services. Today, pathways of care for people with mental health needs can involve a large range of different types of services provided and financed by the health, social care and other societal sectors. Such services include, among others, emergency and crisis intervention services, psychiatric hospitals, psychiatric units in general hospitals, day hospitals and day centers, ambulatory psychiatric services, psychotherapists, rehabilitation workshops, mobile services (such as assertive community treatment teams) and residential facilities of all kinds (from supported flats to nursing homes).

Still, available routine data on mental health service utilization are very limited. As has been pointed out, both within most countries and on an international level, it is almost always just hospital data that are reported on a regular basis. Not only do these hospital data suffer from comparability problems, but they also create the wrong impression that mental health care is nothing more than hospital treatment (Katschnig et al. 2006). Thus, while service systems for mental health problems have become increasingly complex, monitoring of service use is still at the stage where it was 100 years ago.

Difficult as the task may look like, attempts have been made to go beyond hospital data and include also psychiatric outpatient data and community mental health services, by setting up psychiatric case registers. Before discussing such case registers, another challenge of monitoring service use by persons with mental health problems has to be examined.

\section{Utilization of non-psychiatric services by persons suffering from mental disorders}

Monitoring service utilization by persons with mental disorders has become even more challenging, since it has been known that, in addition to specialist mental health services, all types of general health services are utilized by these persons. The general practitioner in particular can play a prominent role (Ansseau et al. 2004), but non-psychiatric units in general hospitals are also most relevant (Krautgartner et al. 2006). (In fact in the international statistical reports, discharges with a psychiatric diagnosis are reported for all hospitals in a country, but it does not become clear, from what type of hospital bed - psychiatric or non-psychiatric - the reported discharges have occurred; Katschnig et al. 2006). And increasingly nonpsychiatric professions are offering services for persons with mental disorders (Katschnig, 2010). There are several possible explanations as to why nonpsychiatric services are utilized so often: the larger number and easier accessibility of general health-care services, the frequent co-morbidity of somatic and psychiatric disorders, misinterpretation of symptoms and fear of stigma and discrimination when using specialized psychiatric services.

In addition, also in services of social, educational, judicial and other sectors of society patients with mental health problems show up (Priebe et al. 2005), let alone at natural healers and practitioners of alternative forms of medicine. A case vignette-based general population study in Germany found that only a minority of interviewees recommended to see a psychiatrist as the first choice in case of mental health problems (Riedel-Heller et al. 2005). Similar results were reported for Austria and Australia (Jorm et al. 2000).

It is obviously an impossible task to monitor, i.e. report on a routine basis, contacts by persons with mental disorders in all of these different types of service. But it might be possible to include at least nonpsychiatric health services. We shall discuss this possibility below. Before exploring it, yet another already mentioned problem of monitoring service utilization has to be discussed, the 'event' (or 'episode') relatedness as opposed to 'patient centredness' of routinely reported data on service utilization.

\section{Event (episode) of care vs person relatedness of monitoring service utilization by persons with mental disorders}

Routinely reported indicators for service utilization are as a rule event related, i.e. they represent single instances of service use without relating them to each 
other (Katschnig et al. 2006). The already-quoted typical examples are frequencies (or population related rates) of hospital discharges and average length of stay of inpatient episodes.

While for some purposes such event-related indicators may be useful, they do not allow for the depiction of variations in service use in the sense that some patients may use a service system or a part thereof again and again or for prolonged time periods - so-called 'heavy utilizers'. For instance, a record linkage study in Austria found that $50 \%$ of bed days in psychiatric inpatient units were consumed by only $17 \%$ of patients, whereas $83 \%$ of patients were responsible for the other $50 \%$ of bed usage (Krautgartner et al. 2002). In a record linkage study on hospital episodes of surgical patients in Norway, Petersen (Petersen, 2010) has suggested that the DRG hospital financing system leads to too early discharges of patients, to more readmissions and to a need for increased reimbursement from the state, with the consequence that more and more financial resources are transferred to the hospital sector and more and more of these resources are used to treat the same patient more than once.

In contrast to the importance of such findings of specific studies, published routine statistics just provide the numbers of hospital episodes, regardless of first or readmission status, and cannot be used for such analyses. Austria, for instance, has the highest rate of hospital discharges per 1000 population among OECD countries (more than twice as many as, for instance, Spain or Portugal, and five times as many as Mexico; OECD, 2010), but it is not clear as to what this actually means for service planning and evaluation (how many of these discharges are by different patients, and how many by the same?)

Moreover, the traditional event-related indicators do not allow for the description of the interconnectedness of service utilization across different service types, such as typical patient pathways from hospital to outpatient services and back (let alone the time dimension on how fast and how often such transitions occur), or the referral of patients from hospitals to residential care home ('trans-institutionalization', instead of 'de-institutionalization').

In today's complex landscape of services for people with mental disorders the number of possible interfaces between services is increasing. Together with the existing fragmented financing systems, these interfaces are increasingly difficult to manage in terms of providing optimal care pathways adjusted for diagnosis, disability, stage of the disorder and needs of the patient and his/her family. Often cost shifting reasons and the interests of the institution dominate over the interests of the patients and their families. But it is difficult to demonstrate this without linking patient records.
Toward routine mapping of pathways of care of patients with mental disorders

Psychiatric case registers

Attempts at describing on a routine basis the utilization of all mental health services in circumscribed geographical areas include the setting up of so-called psychiatric case registers (Tansella et al. 2006; Perera et al. 2009) several decades ago, when the aim was to monitor the setting up of community mental health services. Some of these case registers have been shut down due to data protection concerns or because of lack of funding. The few remaining, how useful they might be for other purposes, are of limited use for comprehensive mapping of pathways of care of patients with mental disorders, because, as a rule, they do not include non-psychiatric health-care services. Even more important is the fact that these registers were usually set up in geographical areas, where the philosophy was to promote community mental health services, and that they are therefore not representative of a larger region or a whole country.

In a few places (e.g. Denmark; Federal State of Western Australia) countrywide psychiatric case registers exist (Munk-Jorgensen \& Mortensen, 1997). But also these do not include the use of non-psychiatric services, or only to a limited degree (Morgan \& Jablensky, 2010). Nevertheless, one or the other of the national case registers, where each member of the population has a unique identification number (as in Denmark), may get access to other databases and link the use of psychiatric services with those dedicated to general health care.

\section{Record linkage of provider payment data using pseudonymized patient records}

Two recent pilot studies in Austria (Katschnig \& Endel, 2010, Katschnig et al. 2010b) set out to explore the possibility of linking inpatient and outpatient health service utilization data (across different types of psychiatric and non-psychiatric services) of psychiatric patients after discharge from the hospital, and to describe 1-step 'pathways of care', i.e. to describe where and when patients showed up in a health service after discharge.

Austria has an obligatory health insurance system with around $98 \%$ of the population insured, however, with many different health insurers and patient records in many different databases. Since a unique personal social insurance number is recorded whenever a health service is used, records could be principally linked in order to identify typical pathways of care. The two studies were carried out in cooperation with the Main Association of Austrian Social Security Institutions that has created the possibility to link 
patients' records across all Austrian Social Security Institutions and all types of services.

Until recently linking of data from different providers was prevented out of data protection reasons. Newly available techniques of 'pseudonymization' have opened a way to such record linkage (Quantin et al. 2008; Weerasinghe et al. 2008). Among other problems the issue of different semantics in different databases had to be approached. These and similar methodological issues of this record linkage project (e.g. issues such as in which service to start the pathway, how to deal with unclear dates of service contact, issues of probabilistic matching, deaths during followup, etc.) are described in detail in a report to the Austrian Ministry of Health that has financed this study (Katschnig et al. 2010a).

Some quite unexpected results have emerged in this study (Fig. 1). Patients were more often readmitted to non-psychiatric hospital beds than to psychiatric beds, patients attended much more often secondary nonpsychiatric ambulatory services than psychiatric ones and $92 \%$ of those discharged from a psychiatric hospital bed saw their general practitioner within 1 year (a very similar result had been obtained in the same part of Austria 25 years ago by Katschnig et al. 1986, who at that time had to use a very cumbersome procedure of interviewing general practitioners). It is quite clear from these results that mapping only specialized psychiatric service utilization gives an incomplete picture of service utilization. Also, it is evident that psychiatric and psychosocial expertise should be made available in non-psychiatric services. Incidentally, a recent hospital record linkage study in Switzerland showed that patients with a psychiatric discharge diagnosis also have a higher utilization of non-psychiatric than of psychiatric hospital beds (Frick \& Frick, 2010).

The available databases allows one to analyze potential determinants for these findings and to answer questions such as: Is the pattern different for different psychiatric diagnoses? Is it the easier accessibility of non-psychiatric services in rural areas which matters? Is it the comorbidity with physical disorders? Also, it will be possible to explore longer than just 1-step pathways.

In sum, it proved to be feasible to link records across different providers in a fragmented health insurance system by using techniques of pseudonymization. Limitations include that, by nature of the data available, utilization of social services, which is known to be quite high among psychiatric patients, could not be analyzed, and that the utilization of privately paid doctors who have no contract with social health insurance, could not be included in this study.

\section{Outlook}

A recent OECD publication on the availability of information for measuring and comparing quality of mental health care across OECD countries (Garcia Armesto et al. 2008) sees promising developments with regard to a 'unique patient identifier' in a number of countries, and formulates several recommendations that such identifiers should be implemented in order to be able to track patients across settings and levels of care, and to monitor continuity of care and links between mental and physical health.

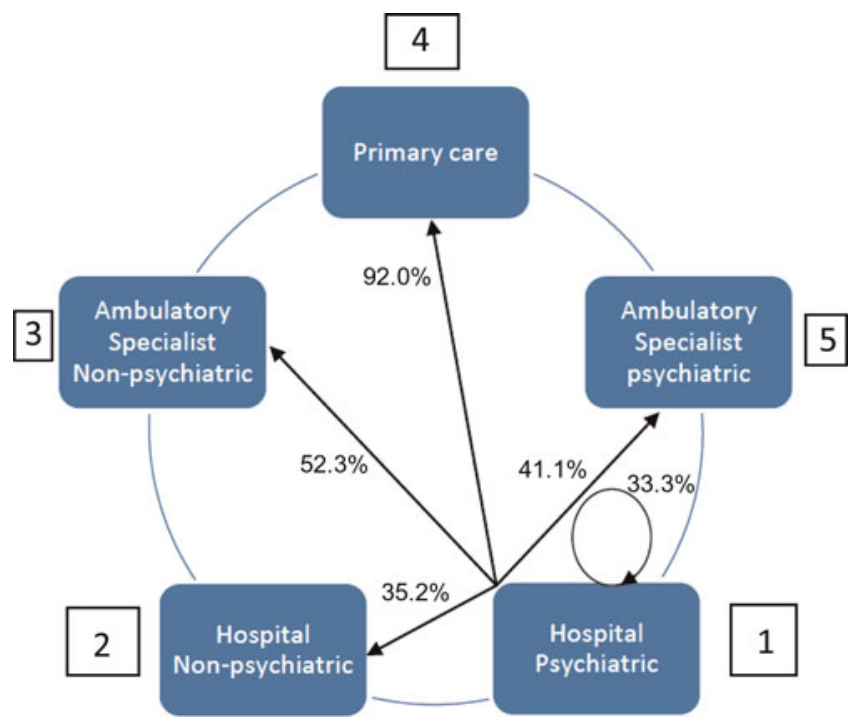

Fig. 1. Probability of contacting five types of services within 1-year after discharge from a psychiatric hospital bed - multiple utilization of different services possible ( $N=3821$ first discharges in 2006 for all 1256856 inhabitants of the Federal State of Lower Austria aged 19+ years). 
It must be added, however, that such a unique patient identifier is only the prerequisite for tracking patients. It has to be considered that in many countries, especially in federally organized and health insurance countries, historically grown different semantics are used in different databases and that an agreement on a minimal basic dataset has to be established before linking patient records. Also, while technically possible, pseudonymization out of data protection reasons might pose a greater challenge than thought, especially if probabilistic matching has to be used in addition to pseudonymization. Furthermore, the quality of administrative data has to be checked carefully (Morgan \& Jablensky, 2010). Finally, it has to be made clear that mapping pathways of care in itself does not allow drawing conclusions about the quality of care. However, routinely monitoring such pathways may lead to discovering deficiencies in the care for persons with mental disorders, and to spotting wrong incentives and disincentives in the provider payment systems in relation to quality of care.

It is no question that the increasing use of electronic health records will facilitate record linkage in the not-too-distant future - if data protection is taken care of adequately. It will allow the mapping of pathways of care for persons with mental disorders on a routine basis. The big challenge, apart from those mentioned above, is the inclusion of primary care, of community mental health services and of services that do not belong to the health-care system, but are relevant nevertheless for providing adequate care for persons suffering from mental disorders.

These and related issues are being tackled in a 7th framework project of the European Commission (REFINEMENT - Financing Systems' Effects on the Quality of Mental health care in Europe, coordinated by the University of Verona), where pathways of care and financing mechanisms will be studied in their relationship to quality of care and outcome for persons with mental disorders in nine European countries. The availability of such information is critical in supplementing visions about the future of mental health care, allowing to formulate and to answer the appropriate questions about the improvement of mental health care.

\section{Acknowledgements}

I would like to thank Raluca Sfetcu and Gottfried Endel for comments on an earlier version of this paper.

\section{References}

Amaddeo F, Zambello F, Tansella M, Thornicroft G (2001). Accessibility and pathways to psychiatric care in a community-based mental health care. Social Psychiatry and Psychiatric Epidemiology 36, 500-507.

Ansseau M, Dierick M, Buntinkx F, Cnockaert P, De Smedt J, Van Den Haute M, Vander Mijnsbrugge D (2004). High prevalence of mental disorders in primary care. Journal of Affective Disorders 78, 49-55.

Botha UA, Koen L, Joska JA, Parker JS, Horn N, Hering LM, Oosthuizen PP (2010). The revolving door phenomenon in psychiatry: comparing low-frequency and high-frequency users of psychiatric inpatient services in a developing country. Social Psychiatry and Psychiatric Epidemiology 45, 461-468.

Burns T, Catty J, White S, Clement S, Ellis G, Jones IR, Lissouba P, Mclaren S, Rose D, Wykes T (2009).

Continuity of care in mental health: understanding and measuring a complex phenomenon. Psychological Medicine 39, 313-323.

Byrne SL, Hooke GR, Page AC (2010). Readmission: a useful indicator of the quality of inpatient psychiatric care. Journal of Affective Disorders 126, 206-213.

Durbin J, Lin E, Layne C, Teed M (2007). Is readmission a valid indicator of the quality of inpatient psychiatric care? Journal of Behavioral Health Services and Research 34, 137-150.

EC (European Commission) (October 2010). Special Eurobarometer 345, Mental Health (http://ec.europa.eu/ health/eurobarometers/index_en.htm). Accessed November 2010.

EUROSTAT (2010). http://epp.eurostat.ec.europa.eu/portal/ page/portal/health/public_health. Accessed November 2010.

Frick U, Frick H (2010). 'The psychiatric revolving door': facts from the national discharge statistics of Switzerland. In: Third European Public Health Congress, 2010 Amsterdam. European Journal of Public Health 26, Volume 20 (Suppl 1), p. 26.

Garcia Armesto S, Madeiros H, Wei L (2008). Information availability for measuring and comparing quality of mental health care across OECD countries. OECD Health Technical Papers No. 20. OECD: Paris.

Goldberg D, Huxley P (1980). Mental Illness in the Community: The Pathway to Psychiatric Care. Taylor and Francis: London.

Healy D, Savage M, Michael P, Harris M, Hirst D, Carter M, Cattell D, Mcmonagle T, Sohler N, Susser E (2001). Psychiatric bed utilization: 1896 and 1996 compared. Psychological Medicine 31, 779-790.

Jacobs R, Mcdaid D (2009). Performance assessment in mental health services. In Performance Measurement for Health System Improvement: Experiences, Challenges and Prospects (ed. P. M. E. Smith, S. Leatherman and I. Papanicolas), pp. 426-472, Cambridge University Press: Cambridge.

Jones IR, Ahmed N, Catty J, Mclaren S, Rose D, Wykes T, Burns T (2009). Illness careers and continuity of care in mental health services: a qualitative study of service users and carers. Social Science and Medicine 69, 632-639.

Jorm AF, Angermeyer M, Katschnig H (2000). Public knowledge of and attitudes to mental disorders: a limiting factor in the optimal use of treatment services. In Unmet Need in Psychiatry: Problems, Resources, Responses (ed. 
G. Andrews and S. Henderson), pp. 399-413, Cambridge University Press: Cambridge.

Katschnig H (2010). Are psychiatrists an endangered species? Observations on internal and external challenges to the profession. World Psychiatry 9, 21-28.

Katschnig H, Breier P, Constantopoulos A, Dragomirecka E, Rancans E, Reneses B, Angerer K, Obernosterer E (2006). Monitoring service utilisation. In Improving Mental Health Information in Europe - Proposal of the MINDFUL project (ed. J. Lavikainen, T. Fryers and V. Lehtinen), pp. 66-77, STAKES: Helsinki.

Katschnig H, Eichberger G, Schimek M, Seidl L (1986). The role of the genera practitioner in the care of discharged psychiatric patients - a pilot study in a rural area. In Mental Illness Inprimary Care Settings (ed. M. Shepherd,

G. Wilkinson and P. Williams), pp. 226-232, Tavistock Publications: London and New York.

Katschnig H, Endel G (2010). Identifying psychiatric patients' pathways through the health care system by record linkage and pseudonymisation 1: linking inpatient and outpatient data of a large health insurer in Austria. Poster presentation, 26th PCSI Conference, 2010 Munich (http:// pcstest.x-coop.de/index.php?option=com_content\&view= article\&id=70\&Itemid=79).

Katschnig H, Endel G, Endel F, Filzmoser P, Weibold B (2010b). Identifying psychiatric patients' pathways through the health care system by record linkage after pseudonymisation 2: linking inpatient and outpatient data for the total population of a province of Austria. Poster presentation, 26th PCSI Conference, 2010 Munich. (http:// pcstest.x-coop.de/index.php?option=com_content\&view= article\&id=70\&Itemid=79).

Katschnig H, Endel G, Endel F, Weibold B (2010a). Inanspruchnahme-Pfade von Patienten mit Psychiatrischen Diagnosen durch das Gesundheitsversorgungssystem: Aus dem Krankenhausbett in die ambulante Versorgung und zurück 2.Teil ('Psypfade 2 - PP2'). Federal Ministry of Health: Vienna.

Krautgartner M, Alexandrowicz R, Benda N, Wancata J (2006). Need and utilization of psychiatric consultation services among general hospital inpatients. Social Psychiatry and Psychiatric Epidemiology 41, 294-301.

Krautgartner M, Scherer M, Katschnig H (2002). Psychiatrische Krankenhaustage: Wer konsumiert die meisten? - Eine Record Linkage Studie über fünf Jahre in einem österreichischen Bundesland. [Days in psychiatric hospitals: who consumes most of them? A five-year record linkage study of 'Heavy Users' in an Austrian province]. Psychiatrische Praxis 29, 355-363.

Kutzin J (2001). A descriptive framework for country-level analysis of health care financing arrangements. Health Policy 56, 171-204.

Lave JR (2003). Developing a Medicare prospective payment system for inpatient psychiatric care. Health Affairs (Millwood), 22, 97-109.

Morgan VA, Jablensky AV (2010). From inventory to benchmark: quality of psychiatric case registers in research.
British Journal of Psychiatry: The Journal of Mental Science 197, 8-10.

Munk-Jorgensen P, Mortensen PB (1997). The Danish Psychiatric Central Register. Danish Medical Bulletin 44, 82-84.

OECD (2010). Health at a Glance: Europe 2010. OECD Publishing: Paris.

Perera G, Soremekun M, Breen G, Stewart R (2009). The psychiatric case register: noble past, challenging present, but exciting future. British Journal of Psychiatry 195, 191-193.

Petersen S (2010). Hospital reimbursement and readmissions. Norway 2002, 2005 and 2008. BMC Health Services Research 10, A14.

Priebe S, Badesconyi A, Fioritti A, Hansson L, Kilian R, Torres-Gonzales F, Turner T, Wiersma D (2005). Reinstitutionalisation in mental health care: comparison of data on service provision from six European countries. British Medical Journal 330, 123-126.

Quantin C, Fassa M, Coatrieux G, Trouessin G, Allaert FA (2008). Combining hashing and enciphering algorithms for epidemiological analysis of gathered data. Methods of Information in Medicine 47, 454-458.

Riedel-Heller SG, Matschinger H, Angermeyer MC (2005). Mental disorders - who and what might help? Help-seeking and treatment preferences of the lay public. Social Psychiatry and Psychiatric Epidemiology 40, 167-174.

Rossi A, Morgan V, Amaddeo F, Sandri M, Tansella M, Jablensky A (2005). Psychiatric out-patients seen once only in South Verona and Western Australia: a comparative case-register study. Australian and New Zealand Journal of Psychiatry 39, 414-422.

Tansella M, Amaddeo F, Burti L, Lasalvia A, Ruggeri M (2006). Evaluating a community-based mental health service focusing on severe mental illness. The Verona experience. Acta Psychiatrica Scandinavica 113(Suppl. 429), 90-94.

Thornicroft G, Tansella M (2002). Balancing community-based and hospital-based mental health care. World Psychiatry 1, 84-90.

Weerasinghe D, Rajarajan M, Elmufti K, Rakocevic V (2008). Patient privacy protection using anonymous access control techniques. Methods of Information in Medicine 47, 235-240.

Wendt C, Frisina L, Rothgang H (2009). Healthcare system types: a conceptual framework for comparison. Social Policy and Administration 43, 70-90.

Weyns L, De Paepe L, Moons P (2006). Kwaliteit van ontslagmanagement bij psychiatrische patienten: een literatuurstudie naar performantiemaatstaven. Acta Hospitalia 46, 33.

WHO (2005). Mental health: facing the challenges, building solutions. Report from the WHO European Ministerial Conference 2005. World Health Organization Regional Office for Europe: Copenhagen.

WHO-HFA (World Health Organization - Health For All) (2010). (http://www.euro.who.int/en/what-we-do/ data-and-evidence/databases/european-health-for-alldatabase-hfa-db2). Accessed November 2010. 